\title{
Validation and measurement invariance of the Compound PsyCap Scale (CPC-12): a short universal measure of psychological capital
}

\author{
Silvia Platania ${ }^{1 *}$, and Anna Paolillo \\ 1 University of Catania, Department of Educational Sciences, Section of Psychology Catania (Italy) \\ 2 Kingston University London, Department of Management, Kingston Business School (UK)
}

Titulo: Validación y medición de invarianza de la Escala Compound PsyCap (CPC-12): una medida universal corta de capital psicológico.

Resumen: Lorenz y sus colegas desarrollaron la Escala Compound PsyCap (CPC-12) para ampliar este enfoque de dominio específico; sin embargo, no se realizó ninguna verificación adicional de su idoneidad en diferentes muestras / entornos. El presente trabajo investigó las propiedades psicométricas de una adaptación italiana del CPC-12 con el objetivo de verificar su aplicabilidad en muestras donde la redacción de los ítems de las medidas existentes de PsyCap podría no ser adecuada (por ejemplo, estudiantes y desempleados). El estudio $1(n=450)$ examinó la estructura factorial de la escala. El estudio $2(n=255)$ avanzó en la validación anterior de la CPC-12 al probar su equivalencia de medición entre sexos a través de MCFA. Los resultados confirmaron una estructura factorial de un orden superior con cuatro factores de primer orden; se encontró que la escala era invariante en todos los sexos. Los hallazgos avanzaron la afirmación general de la CPC-12 de ser adecuada para su aplicación en múltiples contextos, incluidos el deporte, la educación, la orientación profesional, as como los entornos laborales típicos y atípicos.

Palabras clave: Capital psicológico. Validación. Equivalencia de medida. Invariancia. Psicometría. Psicología positiva.

\section{Introduction}

Positive psychology is the new movement initiated by Martin Seligman (Seligman \& Csikszentmihalyi, 2000), which redirected completely the focus of psychology and psychological research from mental illnesses to human strengths and potentials. Within the positive psychology movement, Luthans (2002) identified and proposed what he called positive organizational behaviour (POB), which focused on positive psychological states and capacities that can be measured, developed and managed in the workplace and that can result in performance improvement. Those psychological capacities include self-efficacy, hope, optimism and resiliency and they are commonly referred to as positive psychological capital (PsyCap; Luthans \& Youssef, 2004).

Overall, these four positive dimensions depict an agentic state of mind that, according to the COR theory (Hobfoll, 1989; 1998), represents an aggregate of psychological resources. That explains why the term capital is used, since PsyCap describes a higher-order construct that designates the shared variance of self-efficacy, hope, optimism, and resiliency. Specifically, this second-order aggregate showed to have a higher impact on individual and organizational outcomes compared to each of its four components individually

* Correspondence address [Dirección para correspondencia]: Silvia Platania. University of Catania, Department of Educational Sciences, Section of Psychology, Via Biblioteca n²4, 95124, Catania (Italy). E-mail: splatani@unict.it (Article received: 9-10-2020, revised: 7-4-2021, accepted: 11-4-2021)
Abstract: The Compound PsyCap Scale (CPC-12) was developed by Lorenz et al. (2016) to broaden the application of psychological capital, since usually tied to workplace settings; however, no further verification of its suitability across different samples was performed. The present work investigated the psychometric properties of an Italian adaptation of the CPC12 with the aim of verifying its applicability in samples where the item wording of the existing measures of PsyCap might not be suitable (e.g., students and unemployed people). Study $1(n=450)$ examined the factor structure of the scale. Study $2(n=255)$ advanced the previous CPC-12 validation by testing its measurement equivalence across gender through MCFA. Results confirmed a one higher-order factor structure with four first-order factors, the scale was found to be invariant across gender. The findings advanced the general claim of CPC-12 to be suitable for application in multiple contexts, including sport, education, vocational guidance, as well as typical and atypical work settings.

Keywords: Psychological capital. Validation. Measurement equivalence. Invariance. Psychometrics. Positive psychology.

(e.g., Luthans, Avolio et al., 2007); this effect would occur because PsyCap incorporates the coping mechanisms that the four individual components have in common (Avey et al., 2011).

There are few theoretically based, well-validated measures of psychological capital and the most commonly used is the Psychological Capital Questionnaire (PCQ; Luthans, Youssef et al., 2007). The 24 items questionnaire was developed using pre-existing, published measures of selfefficacy (Parker, 1998), hope (Snyder et al., 1996), optimism (Scheier \& Carver, 1985) and resilience (Wagnild \& Young, 1993), but adapted for application in the work setting. However, limitations of the psychometric properties of this measure have been indicated (e.g., Dawkins et al., 2013; Hackman, 2009); criticisms have been based on the fact that the original scales used to develop the PCQ were mostly validated in non-organizational settings (Little et al., 2007). The authors have acknowledged some of these critics and concede that the methods used to develop the PCQ may undermine its construct validity in organizational settings ( $\mathrm{Lu}-$ thans et al., 2010; Luthans et al., 2012). Nevertheless, the PCQ has been predominantly used in employee, manager and student samples (Dawkins et al., 2013); therefore, it can be considered "a domain-specific measure" (Lorenz et al., 2016, p. 2), since its items are closely tied to the workplace (i.e. "I feel confident contributing to discussions about the company's strategy"). Some adaptations of the PCQ have been developed to tailor it to some specific contexts, such as health (Implicit Psychological Capital Questionnaire-Health; 
Harms et al., 2017), academia (Academic Psychological Capital Questionnaire A-PCQ, Luthans et al., 2012) and crosscultural interactions (Dollwet \& Reichard, 2014). Nevertheless, the previous research focused mainly on the workplace domain-specific measure, by showing how PsyCap is associated with desirable employee attitudes, behaviors and performance (see the meta-analysis of Avey et al., 2011).

Although the PCQ has been focused and developed on the workplace domain, there are certain organisational contexts where the item wordings of the PCQ might not be suitable, i.e., volunteering and small organizations (Lorenz et al., 2016) and within the new forms of agile and atypical work (e.g., contractors and remote workers), where individuals do not necessarily have direct contacts with other colleagues and/or do not participate to meetings with other company members.

Furthermore and beyond the workplace-specific benefits, research has found evidence of PsyCap leading to an improved general psychological and physical well-being by the reduction of stress (Baron et al., 2016). Specifically, PsyCap represents personal resources that help individuals achieve success in a wide range of work and non-work-related activities (Culbertson et al., 2010; Peterson et al., 2011).

Additionally, PsyCap (in its individual components as well as a higher-order construct) is usually associated with job satisfaction (as occupational well-being is commonly operationalised as job satisfaction), as well as to job meaningfulness (manifested in being engaged and committed to work; Görgens-Ekermans \& Steyn, 2016; Jiang et al., 2015); however, research found that PsyCap is reliably related to a much broader definition of well-being that is more indicative of human happiness, flourishing, and thriving (e.g., life satisfaction; Culbertson et al., 2010).

Such spillover effect from individual's work life to his/her personal life is supported by Fredrickson's (2001) broaden-and-build theory of positive emotions, which states that positive thoughts and well-being create a positive spiral generating further positive experiences, thoughts, and feelings which, in turn, is beneficial to optimal functioning.

Overall, the above-mentioned results lead to the consideration that PsyCap consists of more general constructs (hope, optimism, self-efficacy and resilience) and that it is shown to be linked to outcomes of general importance for the individual.

For that reason, it is important to have a general validated measure of psychological capital, which can be applicable across broader life domains (e.g., education and vocational guidance), as well as non-traditional work settings (e.g., unemployment and agile working).

\section{Psychological capital components}

Going through each of the four constructs comprising Psychological Capital, self-efficacy draws from Bandura's social cognitive theory (Bandura, 1997; 2012) and it is defined as one's confidence in his or her ability to mobilize the moti- vation, cognitive resources, and courses of action necessary to achieve certain levels of performance (Stajkovic \& Luthans, 1998). People with high self-efficacy generally have a stronger belief in their ability to control outcomes successfully accomplish their goals and succeed when facing difficult challenges compared to those less self-efficacious (Bandura, 1997). Although task-specific and generalized selfefficacy are distinct constructs (Stajkovic \& Luthans, 1998), the majority of self-efficacy researchers (and of the measures of self-efficacy included in the PsyCap scales) have focused on task-specific or state-like self-efficacy (SSE) exclusively, while ignoring the generality dimension of it (Chen et al., 2001). However, general self-efficacy (GSE) is much more resistant to transitory influences than is SSE (Eden, 1988). The most powerful antecedent of GSE is the aggregation of previous experiences (Shelton, 1990; Sherer et al., 1982); specifically, GSE would emerge over one's life span as one accumulates successes and failures across different task domains (Shelton, 1990). Therefore, individuals with high GSE will generalize their existing expectations of their abilities to perform tasks in different undertakings (Bandura, 1997) and in new situations (Sherer et al., 1982). This also means that, if SSE predicts highly specific outcomes best (see Bandura, 1997), GSE can be more useful when facing unknown challenging situations (Grether et al., 2018) and when the performance under scrutiny is generalized (Chen et al., 2001). That is the reason why the PsyCap scale validated in the present study included a measure of a general self-efficacy, rather than a domain-specific one.

Hope is based on the interaction between two factors: agency (goal-directed energy) and pathways (Snyder et al., 1996). People are driven to accomplish their goals by their sense of agency, which provides them with the motivation to invest the energy necessary to succeed at a specific task, whereas pathways refer to the way or means by which that task may be accomplished (Luthans et al., 2008). Those with high levels of hope are also more capable to generate alternative pathways towards the accomplishment of their goals if the original ones have been blocked (Luthans \& Youssef, 2004; Luthans et al., 2008). Higher hope is associated with specific goal-setting and goal-accomplishment behaviors that may increase the likelihood of successful goal attainment (Cheavens et al., 2019). Dispositional hope has been showed to be a strong predictor of domain-specific outcomes, such as career exploration (Hirschi et al., 2015), as well as to be positively related to career-decision self-efficacy among adolescents, college students and working adults (Hirschi, 2014; In, 2016). Previous studies have also helped with proving how established positive effects of context-general hope has positive effects on outcomes in the educational, health, and psychological well-being domains (Chang et al., 2019; Snyder, 2002). The above-mentioned research has utilised a notion of hope that is not restricted to a particular life domain, therefore showing how more context-general traits and states are related to different specific outcomes. This, 
therefore, calls for the need of a state measure of hope when assessing psychological capital across different scopes.

Optimism refers to an individual's expectancy of positive outcomes (Scheier et al., 2001). It involves a positive explanatory style that attributes positive events to internal, permanent, and pervasive causes, and negative events to external, temporary, and situation specific ones (Seligman, 1998). Those high in optimism generally build positive expectancies that motivate them to pursue their goals and deal with difficult situations (Newman et al., 2014). Many studies have shown the beneficial aspects of optimism for general and specific domains of life, including physical health, adjustment to college, work productivity, prevention of depression, coping with unemployment (Aspinwall, 2005), career adaptability and life satisfaction (Santilli et al., 2017) and effective decision-making styles (Magnano et al., 2015). This underlines how optimism, operationalised as a general individual resource, can have an impact on a broad range of areas of life.

Resilience is the capacity to bounce back from adversity, uncertainty, failure and adapt to changing and stressful life demands (Masten \& Reed, 2002; Tugade \& Fredrickson, 2004). Individuals high in resilience tend to be better at adapting in the face of negative experiences and changes in the external environment (Luthans et al., 2006), by enhancing the assets and/or reducing the risk factors within individuals and/ or their environment. High resilience has been associated with good physical and mental health (Schure et al., 2013), as well as to more work-specific outcomes (e.g., resilience as predictor of achievement motivation; Magnano et al., 2016), demonstrating the utility of conceptualising and operationalising it as a general construct.

\section{The present study}

Moving from those findings, Lorentz et al. (2016), developed and validated a universal measure of psychological capital in the German context; specifically, the Compound PsyCap Scale (CPC-12) is a 12-items self-report questionnaire, answered on a 6-point Likert scale and composed of four first-order factors (i.e., hope, resilience, optimism, and self-efficacy), loading on a higher factor (PsyCap). The scale has been developed using existing and validated measures of hope (Snyder et al., 1996), optimism (Brandtstädter \& Wentura, 1994; Glaesmer et al., 2008), resilience (Leppert et al., 2008), self-efficacy (Jerusalem \& Schwarzer, 1999; Schyns \& von Collani, 2002) and psychological capital (Luthans, Avolio et al., 2007). The questionnaire has shown very good psychometric properties in terms of factorial structure, external, discriminant and convergent validity. The CPC-12 broadened the domain-specific approach to psychological capital, which was limited to its assessment within the work context and showed how PsyCap could in fact be a general construct and applicable to more areas than $\mathrm{POB}$, such as sports and education. Furthermore, the CPC-12 is also a short and economic alternative in organizational research for sectors where the item wordings of the PCQ might not be suitable, since its correlations with work-related constructs are similar to the PCQ (Lorenz et al., 2016).

Specifically for the Italian context, very few studies have used the construct of Psychological capital, all focusing on their application to the workplace context (Alessandri et al., 2015; Alessandri et al., 2018; Costantini et al., 2017); on the contrary, there are several research on Italian students and adolescents based on the study of the single components of psychological capital in education and career guidance (e.g., self-efficacy as predicting academic achievement; Caprara et al., 2011; optimism as predictor of effective decision-making styles; Magnano et al., 2015).

As mentioned earlier, given the importance of PsyCap in influencing a wide variety of other positive psychological constructs and life domains and since, as a higher-order construct, it has a combined and stronger impact compared to its four components taken individually (Luthans, Avolio et al., 2007), the main aim of the present study is to contribute to the validation of an Italian adaptation of the Compound PsyCap Scale (developed by Lorenz et al., 2016) and it is particularly aimed at (1) examining whether there is any psychometric difference to the whole scale when applied to a different culture; (2) advancing the validation of the CPC-12 by exploring its measurement equivalence across gender (Cheung, 2008; Vandenberg \& Lance, 2000). Specifically, this statistical procedure was not included in the German validation of the scale; nevertheless, it is fundamental to test that the questionnaire is operating in exactly the same way and that the underlying construct has the same theoretical structure and psychological meaning across the groups of interest (Byrne, 2008). (3) Assessing the discriminant validity and criterion validity of the scale. Two studies were carried out to achieve these aims: in the first study, we hypothesized that the CSC-12 scale would show the same factor structure found in the Lorenz and colleagues' study (Hypothesis 1). Furthermore, in the second study, we replicated the best fitting solution from Study 1 and we then hypothesized (Hypothesis 2) that the Italian version of the CPC-12 will show measurement equivalence (Cheung, 2008) across gender (men vs. women); then we hypothesized that for any two latent factors of the CPC-12 Scale, the variance extracted estimate for each of them will be greater than the shared variance between them, thus supporting the discriminant validity of the scale (Hypothesis 3). Finally, we hypothesized that the CPC-12 will show positive and significant correlations with some criterion-related variables (Hypothesis 4). With reference to the latter, the variables taken into consideration and the specific hypotheses regarding the associations between those variables and CPC-12 are discussed below.

\section{Imaginative capability}

Previous studies have found psychological capital to motivate employees in creatively exploring new ideas and proactively taking novel approaches for radical change (Avey et al., 
2012; Huang \& Luthans, 2015; Rego et al., 2012; Sweetman et al., 2011). In the present research, we aimed at verifying that also a general measure of PsyCap can be related to the ability of exploring the unknown, generating new and uncommon ideas and emphasizing the attributes of initiative taking and originality, which is defined as "Imaginative Capability" (Craparo et al., 2018, p. 969), and it is not relevant only to a specific context. For that reason, we hypothesized that CPC-12 will show higher correlation with individual's imaginative capability, compared to the work-domain measure of PsyCap (PCQ; Luthans \& Youssef, 2004).

\section{Psychological meaningfulness}

Since positive individual states of optimism and selfefficacy might result in positive feelings of meaning of work (Görgens-Ekermans \& Steyn, 2016), as well as being resilient can help individuals creating meaning in difficult situations in life and at work (Coutu, 2002), a general measure of psychological capital should be positively related to the meaning individuals give to their work (Lorenz et al., 2016), also known as psychological meaningfulness (Geldenhuys et al., 2014).

\section{Job satisfaction}

Following the results of previous research, finding that people high in PsyCap also reported higher job satisfaction (Luthans et al., 2005; Luthans et al., 2006; Newman et al., 2014), it is expected that people who are hopeful, optimistic, confident to persist and have higher belief in their personal abilities will be more satisfied with their job (Avey et al., 2011; Luthans, Avolio et al., 2007), as they tend to seek pleasure and worth in their job, this leading to a rise in their job satisfaction (Hyo \& Yoon, 20015).

\section{Problem-solving self-efficacy}

This dimension includes self-confidence and belief in one's ability to make decisions (Craparo et al., 2018). Giving that this is a task-specific or state-like self-efficacy (SSE), it is expected to be highly related with a general measure of selfefficacy, as well as with the other components of psychological capital. Moreover, problem solving as a form of active coping is believed to represent an important outcome of hope (Snyder et al., 2001) as well as of resilience and self-efficacy (Li et al., 2018; Li et al., 2013). This would be due to the fact that in the problem-solving process, people's cognitive appraisal influences them to cope with the situation they face by guiding them to evaluate that situation (Dickinson-Delaporte \& Holmes, 2011). This implies that perception-related traits (such as psychological capital) could influence problem solving beliefs.

\section{Proactive personality}

This dimension represents an individual's ability to control their surrounding environment in an active, selfdetermined way (Lorenz et al., 2016). Proactive people search for opportunities, act, show initiative, and persevere until they produce a change (Alarcon et al., 2009). Several studies have found similarities between proactive personality and PsyCap components; in particular, a proactive personality has shown to be predictive of effective coping strategies to deal with stressors (Cunningham \& De La Rosa, 2008), thus showing similarities to resilience. Moreover, proactive individuals are optimistic, as maintaining a positive outlook may serve to keep them more behaviourally engaged (Ironson et al., 2005); furthermore, proactive personality is considered to be very similar to self-efficacy (Schwarzer \&, Schmitz 1999), as proactive people belief in their ability to successfully affect and change their environment. In conclusion, Lorenz et al. (2016) found a high correlation between general PsyCap (measured through CPC-12) and proactive personality. Therefore, it is reasonable to expect a similar result.

\section{PCQ}

The most used and validated measure of Psychological Capital in organisational context (Luthans, Avolio et al., 2007) was also used in the Study 1 to test convergent and discriminant validity of CPC-12. Specifically, we hypothesized a strong positive association between PCQ and CPC12 as tested in Lorenz et al. (2016), a higher positive correlation between CPC-12 and the general measure of imaginative capability compared to the one between the latter and PCQ and a lower (yet positive) correlation between CPC-12 and both job satisfaction and psychological meaningfulness compared to the ones those have with PCQ, due to the fact that PCQ is work-domain specific. This would allow us to establish the practicality and usability of CPC-12 across multiple contexts, both work and non-work related.

\section{Study 1}

\section{Method}

\section{Participants}

Study 1 involved a total of 450 participants (203 men, $45.1 \% ; 247$ women, $54.9 \%$ ). The age of participants ranged between 18 and $58\left(M_{a g e}=35.3, S D=7.8\right), 75.6 \%$ were employees $(24.4 \%$ were temporary workers, $24.2 \%$ working in the health care sector, $27 \%$ working in the educational sector) $24.4 \%$ were University students, most of them worked between 11 and 20 years for the same company (58.2\%). With reference to the educational level, $44.2 \%$ of the sample has completed 13 years of school, whereas the remaining $55.8 \%$ has completed a minimum of 16 years of school. The 
participation was voluntary. Questionnaires were administrated individually and anonymously. Participants were recruited through a link published in several social media groups (e.g. Facebook, Twitter and LinkedIn).

\section{Measures}

The following measures were completed by all participants.

The Compound Psychological Capital Scale (CPC12). The present study used the Compound Psychological Capital Scale (CPC-12; Lorenz et al., 2016), made of 12 items with four dimensions: Hope (measured by three items, e.g., "Right now, I see myself as being pretty successful"), Resilience (measured by three items, e.g., "Sometimes I make myself do things whether I want to or not"), Optimism (measured by three items, e.g., "The future holds a lot of good in store for me") and Self-Efficacy (measured by three items, e.g., "I can solve most problems if I invest the necessary effort"). Items were answered using a 6-point Likert type scale ranging from $1=$ "strongly disagree" to $6=$ "strongly agree". Lorenz et al. (2016) reported a Cronbach's alpha coefficient of .82, in the present study Cronbach's alpha coefficient is .80 (Raykov, 1998).

Following the recommendations made by Beaton et al. (2000), a back-translation procedure has been applied during the adaptation, with the process including the following steps: translation and adaptation of the original scale from German to Italian, back translation and review committee. A bilingual Italian-German interpreter translated the German version of the CPC-12 scale into Italian. This first Italian version was then translated back to German by a bilingual psychologist with doctoral degree. Discrepancies emerging from the comparison between the two versions were discussed by the research team and revisions to the Italian translation of the CPC-12 scale were made. There was no substantial difference between the final Italian version and the original German one.

Imaginative Capability. We used the Imaginative Capability subscale from the Risk Intelligence Scale (Craparo, et al., 2018), to measure the generation of new and potentially useful ideas, emphasizing the attributes of initiative taking and originality. The 6 items of the scale were answered on a 5 -point Likert scale ranging from $1=$ "strongly disagree" to $5=$ "strongly agree". Example of items were "When working on a new project, I explore untraditional approaches". Cronbach's alpha in the original study was .86, in our study it was .83 (Raykov, 1998).

The psychological meaningfulness scale (PMS). We used the Psychological Meaningfulness Scale (PMS; Spreitzer, 1995) to measure the degree of meaning individuals experience within their work-related activities. (Geldenhuys et al., 2014). The scale is made of six items, loading on one factor. Items are answered on a five-point Likert scale varying from 1 = "totally agree" to $5=$ "totally disagree" (e.g. "I feel that the work I do is precious"). Olivier and Rothmann (2007) reported a Cronbach's alpha coefficient of .92, in the present study Cronbach's alpha coefficient was .95 (Raykov, 1998).

The Generic Job Satisfaction Scale. We used the Generic Job Satisfaction Scale (Macdonald \& Maclntyre, 1997) to measure the most relevant dimensions of job satisfaction. The ten items in the scale focused on employee's feelings or reactions towards aspects of their jobs. Each item was answered on a 5-point Likert scale varying from $1=$ "strongly agree" to 5 = "strongly disagree" (e.g., "I feel good about my job"), loading on one single factor. Macdonald and Maclntyre (1997) reported a Cronbach's alpha coefficient of .77, in our study the Cronbach's alpha coefficient was .84 (Raykov, 1998).

The Psychological Capital Questionnaire (PCQ). The Psychological Capital Questionnaire (PCQ) is widely recognized as the standard scale measuring Psychological capital (Luthans, Avolio et al., 2007). In the present study, we used the Italian version of the Psychological Capital Questionnaire (Alessandri et al., 2015) made of 24 items, loading on four factors, specifically: Hope (measured by six items, e.g., "Right now I see myself as being pretty successful at work"), Optimism (measured by six items, e.g., "I always look on the bright side of things regarding my job"), Resilience (measured by six items, e.g., "I usually find a way to handle difficulties at work") and Self-Efficacy (measured by six items, e.g., "I feel confident in representing my work area in meetings with management"). Items were assessed using a 6-point Likert type scale ranging from $1=$ "strongly disagree" to $6=$ strongly agree. Alessandri et al. (2015) reported a Cronbach's alpha coefficient of .81 , in our study Cronbach's alpha coefficient was .93 (Raykov, 1998).

\section{Procedure}

The ethics approval was obtained from the first author's University. All participants were volunteers, no compensation was supplied. Potential attendees were sent a link to a questionnaire available on Google Forms. Participants were recruited by posting the survey link in several online social media groups. The first part of the questionnaire consisted of an informed consent form, where respondents were informed of the voluntary and anonymous nature of their participation, the aim of the research and the fact that they were free to voluntary abandon the study at any moment without any penalty.

\section{Data Analysis}

Linear structural equations models were calibrated to test the hypothesized model. Tests were completed in AMOS 21.0 (Arbuckle, 2012) applying the maximum likelihood method.

A sequence of CFA analyses was carried out on the dataset, to establish the best factor model to fit the data.

The models' goodness of fit was evaluated using the Tucker Lewis Index (TLI), the Comparative Fit Index (CFI), 
the Root Mean Square Error of Approximation (RMSEA) and the Standardized Root Mean Square Residual (SRMR). RMSEA values close to 0.06 are indicative of good fit, values between 0.07 and 0.08 are considered as moderate fit, and values between 0.08 and 0.10 are indicative of marginal fit. With regards to CFI and TLI, higher values show better fit. CFI and TLI values above 0.95 show very good fit, values between 0.90 and 0.95 are indicative of marginally acceptable fit, and values lower than 0.90 indicate poor fit. Furthermore, $\chi^{2}$ values and $\Delta \chi^{2}$ values between the competing models are presented, but they are sensitive to sample size (Meade et al., 2008), so Akaike Information Criterion (AIC) and Bayesian Information Criterion (BIC) were also presented (lower values indicate better fit). $\triangle \mathrm{CFI}$ was also used with values not exceeding 0.01 indicating that the models are equivalent in terms of fit. $\Delta C F I$ was also used with values not exceeding 0.01 indicating that the models are equivalent in terms of fit (Cheung \& Rensvold, 2002). To optimize the sample size, missing values for the relevant items were estimated using Expectation Maximization method. None of the items had more than 5 percent missing values, indicating that this option was appropriate for use (Tabachnick \& Fidell, 2007). Other well-known analytical tools such as correlations were also used, which were implemented by using SPSS 26.0.

\section{Results}

At first, a model with one second-order factor and four firstorder factors (Model 1) was tested, and the following fit indexes were obtained: $\left[\chi^{2}(45)=137.102\right.$, SRMR $=.04$, RMSEA $=.07, \quad$ CFI $=.93, \quad$ TLI $=.90, \quad$ AIC $=203.102$, $\mathrm{BIC}=338.707]$. Model 1 was then compared to a four-factor model (Model 2), made of four first-order factors with covariances among them $\left[\chi^{2}(46)=164.296\right.$, SRMR $=.05$, RMSEA $=.08$, CFI $=.91$, TLI $=.86$, AIC $=228.296$, BIC $=$ 359.792]. The first model of the two showed the best fit to the data, based on fit indexes, AIC and delta Chi-square value $\left[\left(\Delta \chi^{2}\right.\right.$ M2- M1(1) $\left.\left.=27.194\right)\right]$. Model 1 was then compared to a one-factor Model (Model 3), in which all the items were predicted by a single factor $\left[\chi^{2}(52)=250.061\right.$, $\mathrm{SRMR}=.06, \mathrm{RMSEA}=.10, \mathrm{CFI}=.84, \mathrm{TLI}=.80, \mathrm{AIC}=$ 302.061, BIC $=303.612]$ and it showed again the best fit to the data $\left[\left(\Delta \chi^{2} \mathrm{M} 3-\mathrm{M} 1(7)=112.959\right)\right]$. Moreover, all factor loadings were significant at $p<.001$ and varied between .32 and .94, with a mean of .64. Fit indexes for the tested models are presented in Table 1.

Table 1

Fit indexes for models tested in $C F A($ Study 1$)$

\begin{tabular}{|c|c|c|c|c|c|c|c|c|c|}
\hline & $\chi^{2}$ & $\mathrm{df}$ & SRMR & RMSEA & RMSEA 90\%-C.I. & CFI & TLI & $\mathrm{AIC}$ & $\mathrm{BIC}$ \\
\hline Model 1a & $137.102 *$ & 45 & .04 & .068 & $.055-.081$ & .93 & .90 & 203.102 & 338.707 \\
\hline Model $2^{\mathrm{b}}$ & $164.296^{*}$ & 46 & .05 & .076 & $.063-.088$ & .91 & .86 & 228.296 & 359.792 \\
\hline Model 3c & $250.061 *$ & 52 & .06 & .096 & $.081-.104$ & .84 & .80 & 302.061 & 303.612 \\
\hline
\end{tabular}

Note. ${ }^{a}$ Model 1: one second-order factor and four first-order factors. ${ }^{\mathrm{b}}$ Model 2: four first-order factors with co-variances among them. ${ }^{\mathrm{c}}$ Model 3: all the items were predicted by a single factor. $* p<.001$

Cronbach's Alpha was computed for each factor to test reliability and showed good internal consistency of the scale: Hope .80 , Optimism .77, Resilience .77 and Self-Efficacy .84 .

Composite reliability and average variance extracted were: CR .81, AVE .60 for Hope, CR .83, AVE .63 for Optimism, CR .92, AVE .78 for Resilience and CR .82, AVE .61 for Self-Efficacy.

In table 2 we report the items, the overall means with the standard deviations and the means by gender, the normality of the distribution and the factor loading of model 1 considered the most parsimonious, confirming the factorial structure of the scale. Critical values that exceed +2.00 or that are smaller than -2.00 indicate statistically significant degrees of non-normality. Descriptive statistics in Table 2 show that data were normally distributed, with acceptable skewness and kurtosis values. All factors' loadings were significant at $p<$ .001 . The results confirm the goodness of the scale and the normality of the distribution.

Table 3 shows descriptive statistic and correlation matrix for the study variables. The high positive relationship ( $r=$ $.61, p<.001$ ) between PCQ and CPC-12 (including second order factors, hope, optimism, resilience and self-efficacy) confirms that they are two similar but not identical construct (Lorenz et al., 2016). The correlation between CPC-12 and Imaginative Capability is higher than the one between PCQ and Imaginative capability $(r=.46, p<.001$ vs. $r=.32, p<$ .001). Moreover, the correlation between CPC-12 and Psychological Meaningfulness at Work (PMS) is lower than the one between PCQ and PMS $(r=.26, p<.001$ vs. $r=.55, p$ $<.001)$, as well as the correlation between CPC-12 and Generic job satisfaction is lower compared to the correlation between the latter and PCQ $(r=.29, p<.001$ vs. $r=.59, p$ $<.001)$. Those results are in line wine Lorenz and colleagues' findings (2016) as they support both discriminant and convergent validity of the scale; specifically, the higher correlations of CPC-12 with a measure of imaginative capability (not specifically related to a particular context) and the lower correlations with job-related measures of meaningfulness at work and job satisfaction are due to the fact that CPC-12 does not have domain specific traits.

Overall, these results did support our first hypothesis, i.e., that the Italian version of the CSC-12 scale would show the same factor structure found in the Lorenz et al. (2016) (Hypothesis 1). 
Table 2. Descriptive statistic (mean (M), standard deviation (SD), skewness, kurtosis) and factor loading of model 1.

\begin{tabular}{|c|c|c|c|c|c|c|c|c|c|}
\hline & \multirow[t]{2}{*}{ M } & \multirow[t]{2}{*}{ SD } & \multicolumn{2}{|c|}{$\begin{array}{c}\text { Female } \\
(247)\end{array}$} & \multirow{2}{*}{$\begin{array}{c}\text { Male } \\
(203)\end{array}$} & \multicolumn{2}{|c|}{ Skewness } & \multirow[t]{2}{*}{ Kurtosis } & \multirow[t]{2}{*}{$\begin{array}{l}\text { Factor loading } \\
\text { Model } 1\end{array}$} \\
\hline & & & $M$ & $S D$ & & $S D$ & & & \\
\hline $\begin{array}{l}\text { 1. If I should find myself in a jam, I could think of many ways } \\
\text { to get out of it (Hope). }\end{array}$ & 5.33 & .58 & 5.43 & .67 & 5.18 & .51 & -.984 & 1.002 & .735 \\
\hline 2. Right now, I see myself as being pretty successful (Hope). & 5.19 & .66 & 5.52 & .81 & 5.01 & .59 & -.894 & 1.061 & .851 \\
\hline 3. I can think of many ways to reach my current goals (Hope). & 5.20 & .71 & 5.09 & .64 & 5.37 & .79 & -.879 & .783 & .718 \\
\hline 4. I am looking forward to the life ahead of me (Optimism). & 5.48 & .72 & 5.51 & .78 & 5.42 & .69 & -.654 & .020 & .860 \\
\hline 5. The future holds a lot of good in store for me (Optimism). & 4.80 & .54 & 5.06 & .62 & 4.72 & .50 & -.524 & -.144 & .821 \\
\hline $\begin{array}{l}\text { 6. Overall, I expect more good things to happen to me than } \\
\text { bad. (Optimism) }\end{array}$ & 5.23 & .59 & 5,24 & .61 & 5.20 & .57 & -.943 & 1.084 & .691 \\
\hline $\begin{array}{l}\text { 7. Sometimes I make myself do things whether I want to or } \\
\text { not (Resilience). }\end{array}$ & 5.61 & .58 & 5.66 & .60 & 5.52 & .55 & -.962 & 1.743 & .929 \\
\hline $\begin{array}{l}\text { 8. When I'm in a difficult situation, I can usually find my way } \\
\text { out of it (Resilience). }\end{array}$ & 5.24 & .68 & 5.56 & .72 & 5.15 & .64 & -.502 & .191 & .834 \\
\hline 9. It's okay if there are people who don't like me (Resilience). & 5.49 & .52 & 5.55 & .57 & 5.45 & .49 & -.739 & .087 & .887 \\
\hline $\begin{array}{l}\text { 10. I am confident that I could deal efficiently with unex- } \\
\text { pected events (Self-efficacy). }\end{array}$ & 5.23 & .76 & 5.51 & .78 & 5.16 & .69 & -.653 & -.377 & .742 \\
\hline $\begin{array}{l}\text { 11. I can solve most problems if I invest the necessary effort } \\
\text { (Self-efficacy). }\end{array}$ & 4.97 & .63 & 5.07 & .68 & 4.81 & .59 & -.999 & .639 & .681 \\
\hline $\begin{array}{l}\text { 12. I can remain calm when facing difficulties because I can } \\
\text { rely on my coping abilities (Self-efficacy). }\end{array}$ & 5.31 & .71 & 5.34 & .76 & 5.25 & .67 & -.929 & .718 & .901 \\
\hline
\end{tabular}

Table 3

Descriptive statistics and inter-correlations for study $1(\mathrm{~N}=450)$.

\begin{tabular}{ccccccccccccc} 
Descriptive statistics and inter-correlations for study 1 & $(\mathrm{~N}=450)$. \\
\hline$M$ & $S D$ & 1 & 2 & 3 & 4 & 5 & 6 & 7 & 8 & 9 & 10 & 11 \\
\hline
\end{tabular}

\begin{tabular}{|c|c|c|c|c|c|c|c|c|c|c|c|c|c|c|}
\hline & $M$ & & 1 & 2 & $J$ & $T$ & 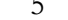 & $\sigma$ & 1 & 0 & , & 10 & 11 & 12 \\
\hline 1. $\mathrm{H}(\mathrm{CPC})$ & 5.24 & .65 & - & & & & & & & & & & & \\
\hline 2. $\mathrm{O}(\mathrm{CPC})$ & 5.17 & .61 & $42^{* *}$ & - & & & & & & & & & & \\
\hline 3. $\mathrm{R}(\mathrm{CPC})$ & 5.45 & .59 & $.46^{* *}$ & $.53^{* *}$ & - & & & & & & & & & \\
\hline 4. $\mathrm{SE}(\mathrm{CPC})$ & 5.17 & .70 & $.44^{* *}$ & $.46^{* *}$ & $.52^{* *}$ & - & & & & & & & & \\
\hline 5. CPC-12 & 5.26 & .49 & $.75^{* *}$ & $.77^{* *}$ & $.80^{* *}$ & $.80^{* *}$ & - & & & & & & & \\
\hline 6. IC & 3.70 & .60 & $.20^{* *}$ & $.33^{* *}$ & $.27^{* *}$ & $.30^{* *}$ & $.46^{* *}$ & - & & & & & & \\
\hline 7. GJS & 5.07 & 1.01 & $.13^{* *}$ & $.27^{* *}$ & $.31^{* *}$ & $.20^{* *}$ & $.29^{* *}$ & $.24^{* *}$ & - & & & & & \\
\hline 8. PM & 5.50 & 1.36 & $.15^{* *}$ & $.17^{* *}$ & $.26^{* *}$ & $.23^{* *}$ & $.26^{* *}$ & $.20^{* *}$ & $.68^{* *}$ & - & & & & \\
\hline 9. PCQ & 5.15 & .57 & $.38^{* *}$ & $.51^{* *}$ & $.56^{* *}$ & $.47^{* *}$ & $.61^{* *}$ & $.32^{* *}$ & $.59^{* *}$ & $.55^{* *}$ & - & & & \\
\hline 10. $\mathrm{H}(\mathrm{PCQ})$ & 5.19 & .74 & $.50^{* *}$ & $.42^{* *}$ & $.31^{* *}$ & $.53^{* *}$ & $.54^{* *}$ & $.19^{* *}$ & $.15^{* *}$ & $.18^{* *}$ & $.65^{* *}$ & - & & \\
\hline 11. $\mathrm{O}(\mathrm{PCQ})$ & 5.37 & .64 & $.39^{* *}$ & $.57^{* *}$ & $.36^{* *}$ & $.48^{* *}$ & $.61^{* *}$ & $.24^{* *}$ & $.22^{* *}$ & $.17^{* *}$ & $.71^{* *}$ & $.38^{* *}$ & - & \\
\hline 12. $\mathrm{R}(\mathrm{PCQ})$ & 5.12 & .77 & $.45^{* *}$ & $.38^{* *}$ & $.60^{* *}$ & $.47^{* *}$ & $.50^{* *}$ & $.23^{* *}$ & $.25^{* *}$ & $.24^{* *}$ & $.59^{* *}$ & $.42^{* *}$ & $.40^{* *}$ & - \\
\hline 13. $\mathrm{SE}(\mathrm{PCQ})$ & 5.06 & .81 & $.43^{* *}$ & $.32^{* *}$ & $.32^{* *}$ & $.55^{* *}$ & $.48^{* *}$ & $.18^{* *}$ & $.26^{* *}$ & $.22^{* *}$ & $.62^{* *}$ & $.39^{* *}$ & $.41^{* *}$ & $.47^{* *}$ \\
\hline
\end{tabular}

Note. PsyCap $=$ Psychological Capital, PCQ $=$ Psychological Capital Questionnaire, CPC-12 = Compound Psychological Capital Scale, IC $=$ Imaginative Capability, GJS= Generic Job Satisfaction, $\mathrm{PM}=$ psychological meaningfulness, $\mathrm{H}(\mathrm{cpc})=$ Hope-Compound Psychological Capital, O(cpc) = OptimismCompound Psychological Capital, R(cpc) = Resilience-Compound Psychological Capital, SE $(\mathrm{cpc})=$ Self efficacy-Compound Psychological Capital, H(pcq) = Hope-Psychological Capital Questionnaire, O(pcq) = Optimism-Psychological Capital Questionnaire, R(pcq) = Resilience-Psychological Capital Questionnaire, $\mathrm{SE}(\mathrm{pcq})=$ Self efficacy-Psychological Capital Questionnaire; $p$ scores: $*<.05, * *<.01, * * *<.001$.

\section{Study 2}

\section{Method}

\section{Participants and procedure}

Study 2 involved 255 participants (53.7\% were men), aged between 18 to 61 years $\left(M_{\text {age }}=28.2, S D=4.1\right) ; 33.7 \%$ were University students, $34.1 \%$ were employed and $32.2 \%$ were unemployed. The participation was completely voluntary. Tests were administrated individually and anonymously. Participants were recruited through a link published in several social media groups.

\section{Measures}

The following measures were completed by all participants.

The Compound Psychological Capital Scale (CPC12). Psychological Capital was measured with the CPC-12 (Study 1, Lorenz et al., 2016), using a 6-point Likert scale ranging from $1=$ "strongly disagree" to $6=$ "strongly agree".

The Proactive Personality Scale. We used the shortened version of Proactive Personality Scale (Seibert et al., 1999; it. adapt., Trifiletti et al., 2009), to measure the inclination to act and change the environment to realize one's goals. Participants answered 10 items using a 7-points Likert scale ranging from $1=$ "absolutely false" to $7=$ "absolutely true". All the items were loading on one factor (example of 
item: "If I see something I don't like, I fix it"). Cronbach's alpha in the original study was .82, in our study it was .88 (Raykov, 1998).

Problem solving Self-Efficacy. We used the Problemsolving Self-Efficacy subscale from the Risk Intelligence Scale (Craparo, et al., 2018), to measure the self-confidence and belief in one's capacity to handle situations. The 6 items of the scale were answered on a 5-point Likert scale ranging from $1=$ "strongly disagree" to $5=$ "strongly agree". Example of items were "I feel able to make decisions even when I don't have all the information". Cronbach's alpha in the original study was .79, in our study it was .71 (Raykov, 1998).

\section{Data Analysis}

Linear structural equation models (Bagozzi, 1994) were calibrated to test the hypothesized model. Tests were completed in AMOS 22.0 applying the maximum likelihood (ML) method. At first, we conducted a confirmatory factor analysis (CFA) to confirm the factor structure of the CPC-12 in an independent sample. Next, a series of multiple group CFA were run, in which different, and progressively more stringent forms of measurement equivalence were tested (Cheung 2008; Vandenberg \& Lance 2000). By establishing whether factor loadings, intercepts and residual variances are equivalent in a factor model that measures a latent concept, we can assure that comparisons that are made on the latent variable are valid across groups or time (Van de Schoot et al., 2012, p.3; Byrne et al., 1989; Campbell at al., 2008).

To assess discriminant validity between factors, the Fornell \& Larcker technique (1981) was performed, comparing the AVE of each latent construct with its shared variance with any other construct of the CPC-12 scale. As noted by Hair et al. (2006), the variance extracted estimates should be greater than the shared variance (e.g. squared correlation), indicating that for any two constructs, the AVE for both of them need to be higher than the shared variance between them (Farrell, 2010; Fornell \& Larcker, 1981). To optimize the sample size, missing values for the relevant items were estimated using Expectation Maximization method. None of the items had more than 5 percent missing values, indicating that this option was appropriate for use (Tabachnick \& Fidell, 2007). Other well-known analytical tools such as corre- lations were also used, which were implemented by using SPSS 21.0.

\section{Results}

\section{CFA}

Results of the CFA for the CPC-12 indicated the following estimates of model fit: $\chi^{2}(47)=121.006$, SRMR $=.04$, $\mathrm{RMSEA}=.07, \mathrm{CFI}=.95, \mathrm{TLI}=.93, \mathrm{AIC}=183.006, \mathrm{BIC}=$ 292.786. Moreover, all factor Loadings are significant at $p$ $<.001$ and varied between .45 and .97 , with a mean of .75 .

\section{MCFA for Gender}

The first multiple-group analysis tested a model of configural invariance (Model 1) by simultaneously evaluating the fit of male and female samples. The fit indices $\left[\chi^{2}(96)=\right.$ 205.274, $p<.001$; TLI $=.93$; CFI $=.94$; SRMR $=.044$; RMSEA $=.076]$ indicated a good fit for this model, supporting an equivalent solution made of one second-order factor with four first-order factors for CPC-12 in the data sets for both men and women (Table 4). The fit of this configural model provides the baseline value against which all subsequently specified equivalence models are compared (Byrne, 2008).

Model 2 was tested for metric invariance (Table 4). More importantly, $\Delta \chi^{2} \mathrm{M} 2-\mathrm{M} 1(11)=15.40$ and $\Delta \mathrm{CFI}=.002$ suggested that Model 2 could be considered equivalent to Model 1. Thus, metric invariance was supported.

Also, measurement scalar invariance (as tested by Model $3)$ and error invariance (Model 4) were found $\left(\Delta \chi 2_{\mathrm{M} 3-\mathrm{M} 2}(12)\right.$ $=6.998, \Delta \mathrm{CFI}=.002 ; \Delta \chi 2_{\mathrm{M} 4-\mathrm{M} 3}(2)=5.42, \Delta \mathrm{CFI}=.001$.

The equivalence in factor variances was tested (Model 5) and it was found to be tenable $\left(\Delta \chi 2_{\mathrm{M} 5-\mathrm{M} 4}(15)=20.89, \Delta \mathrm{CFI}\right.$ $=.000)$. Finally, the equivalence in factor covariances was tested (Model 6) by nesting the respective model with Model 5 , and the result was that it was supported $\left(\Delta \chi 2_{\mathrm{M} 6-\mathrm{M} 5}(3)=\right.$ $10.33, \Delta \mathrm{CFI}=.000)$. Results were totally satisfactory as the model fit proved to be invariant across both populations and they supported our Hypothesis 2 (Table 4).

Table 4

Fit statistics for measurement invariance by gender.

\begin{tabular}{|c|c|c|c|c|c|}
\hline Model & $\chi^{2(\mathrm{df})}$ & CFI & SRMR & RMSEA $[90 \% \mathrm{CI}] p$ close & $\Delta \mathrm{CFI}$ \\
\hline 1. Configural Invariance & $205.274(96)$ & .94 & .04 & $.08(.066-.101)$ & - \\
\hline 2. Metric Invariance & $220.678(107)$ & .93 & .04 & $.07(.054-.080)$ & .002 \\
\hline 3. Scalar Invariance & $227.676(119)$ & .93 & .04 & $.07(.054-.080)$ & .002 \\
\hline 4. Measurement error Invariance & $233.096(121)$ & .93 & .03 & $.07(.054-.080)$ & .001 \\
\hline 5. Structural Variance Invariance & $253.989(136)$ & .93 & .04 & $.07(.054-.080)$ & .000 \\
\hline 6. Structural Covariance Invariance & $264.321(139)$ & .93 & .04 & $.07(.054-.080)$ & .000 \\
\hline
\end{tabular}




\section{Discriminant validity}

Discriminant validity among latent factors (Farrell, 2010) was tested, using the Fornell \& Larcker (1981) technique, by comparing the AVE of each construct with its shared variance with any other construct. It was supported for all the four latent constructs, where the AVE for Hope (.61) and for Optimism (.56) was greater than the shared variance (e.g. square of the correlation) between the two constructs (.22). Similar results were found for Hope (AVE .61) and SelfEfficacy (AVE .70) with their shared variance (.40). Hope (AVE .61) and Resilience (AVE .82) had a shared variance of .55 , whereas Optimism (AVE .56) and Self-Efficacy (AVE .70) had a shared variance of .29 and Optimism (AVE .56) and Resilience (AVE .82) had a shared variance of .30. Finally, Self-Efficacy (AVE .70) and Resilience (AVE. 82) had a shared variance of .35. Thus, Hypothesis 3 was supported.

\section{Criterion validity}

Table 5 presents descriptive statistics, Cronbach's $\alpha$ and bivariate correlations for the variables of Study 2. As expected, the CPC-12 scale showed significant correlations with all the variables, according to literature. Specifically, it showed the highest correlations with Problem-Solving SelfEfficacy $(\mathrm{r}=.48, \mathrm{p}<.001)$, followed by Proactive Personality $(\mathrm{r}=.46, \mathrm{p}<.001)$. The present findings are in line with literature, as psychological capital was found to be strongly related with measures of general self-efficacy (Lorenz et al., 2016), as well as a proactive attitude showed similarities with resilience (Cunningham \& De La Rosa, 2008), optimism and selfefficacy (Schwarzer \& Schmitz, 1999). Therefore, the criterion validity of the scale was confirmed (Hypothesis 4).

Table 5

Descriptive statistics and Pearson correlations between study variables.

\begin{tabular}{|c|c|c|c|c|c|c|c|c|c|c|}
\hline & $N$ & $M$ & $S D$ & $\alpha$ & 1 & 2 & 3 & 4 & 5 & 6 \\
\hline 1.CPC-12 & 255 & 5.26 & .49 & .90 & - & & & & & \\
\hline 2. Hope & 255 & 4.75 & 1.02 & .78 & $.86^{* *}$ & - & & & & \\
\hline 3. Optimism & 255 & 5.03 & .55 & .84 & $.69^{* *}$ & $.47^{* *}$ & - & & & \\
\hline 4. Resilience & 255 & 4.86 & 1.07 & .94 & $.92^{* *}$ & $.74^{* *}$ & $.55^{* *}$ & - & & \\
\hline 5.Self Efficacy & 255 & 4.69 & 1.00 & .88 & $.88^{* *}$ & $.63^{* *}$ & $.54^{* *}$ & $.77^{* *}$ & - & \\
\hline 6. Proactive Personality & 255 & 5.07 & 1.01 & .88 & $.46^{* *}$ & $.35^{* *}$ & $.35^{* *}$ & $.39^{* *}$ & $.40^{* *}$ & - \\
\hline 7. Problem solving Self-Efficacy & 255 & 3.77 & .57 & .71 & $.48^{* *}$ & $.33^{* *}$ & $.33^{* *}$ & $.25^{* *}$ & $.27^{* *}$ & $.35^{* *}$ \\
\hline
\end{tabular}

Note: $*<.05, * *<.001$.

\section{Discussion}

The aim of this study was to examine the psychometric properties of the Compound Psychological Capital Scale (CPC-12) in the Italian context. Several quantitative procedures were used: Confirmative Factor Analyses and Multigroup Confirmative Factor Analyses using Structural Equation Modelling were performed to verify the factorial structure of the scale. Results were consistent with the original findings (Lorenz et al., 2016), suggesting a one higher-order factor structure, composed of four first-order factors. Therefore, the first study revealed that the Italian version of the CPC-12 scale confirmed the stability of the factor structure identified in the original German version.

Further, in the second study we performed a multigroup confirmatory factor analysis to test whether the scale is invariant across gender. The measurement invariance was not assessed in the original study in which the CPC-12 was developed and introduced to literature (Lorenz et al., 2016).

Nevertheless, measurement invariance was tested in the present study to advance the CPC-12 scale validation, as only when such equivalence is established, researchers can proceed with examining mean group differences, having confidence that if any group differences are found, those are due to actual differences in psychological capital and not to an artefact of measurement error (Vandenberg \& Lance, 2000). Results from the multigroup confirmatory factor analysis showed that the same factor solution was invariant across gender (men vs. women). This implies that Italians conceptualize the compound psychological capital in the same way (Byrne, 2008); furthermore, the present study found evidence for metric invariance, uniqueness invariance, scalar and structural invariance, which means that the relationship between the constructs was the same across the groups.

The reliability of the scale, evaluated by computing Cronbach's alpha, composite reliability and average variance extracted (given the multidimensionality of the scale) showed very good values. Discriminant validity between latent factors (Farrell, 2010) was tested using Fornell \& Larcker (1981) technique, and we found that it was fully supported.

Moreover, the results reveal significant high correlations between CPC-12 and PCQ, by demonstrating they are similar but different constructs. At the same time, moderately high correlations were found with domain-specific measures related to work (i.e., psychological meaningfulness and job satisfaction) and with more general constructs of positive psychology (i.e., proactive personality, imaginative capability and problem-solving self-efficacy).

All those finding support the criterion validity of the scale and they advance the general claim of CPC-12 to be applicable in different life and work domains, not only those related to traditional work contexts. Specifically, this means that the item wording of the CPC-12 makes it suitable for more than one sector of application, such as sport, education 
(Lorenz et al., 2016), vocational and career counselling (as appropriate for both students and unemployed people).

The scale can also be used as an alternative in workrelated research for areas where the item wordings of the PCQ might not be suitable, i.e. within new forms of agile and atypical work (e.g., contractors and remote workers), as well as volunteering and small organizations (Lorenz et al., 2016; Platania et al., 2017; Platania et al., 2019).

With specific reference to the Italian context, despite the large amount of literature dedicated to exploring the individual components of PsyCap in association with key educational and work outcomes, there is very limited research on the link between higher-order PsyCap and non-work-related variables. This is a key limitation, because PsyCap may have "a distinct nomological network compared to each of the individual components" (Datu et al., 2016, p. 261). The present study helps in addressing the gap of the lack of a general measure of PsyCap, which can be used in multiple sectors in the European context. More specifically, if some of its firstorder constructs (e.g., self-efficacy) have been shown to predict students' academic achievement (Pisanu \& Fraccaroli, 2019), the use of a comprehensive and validated measure of psychological capital could advance the research in those contexts, by understanding the added value and impact PsyCap can have on those outcomes. At the same time, PsyCap showed to be related to some extra-school behaviors (such as civic sense and attitude towards environmental sustainability; Fraccaroli, 2019), therefore calling even more for the need of a general measurement of such a higher-order non cognitive skill.

\section{Limitations and practical implications}

There are several additional opportunities for future research to improve or extend the present study. First, as the questionnaires were completed by the same individuals at the same point in time, a single-source bias was created. Although statistical steps (Harman's single-factor test) provided an indication that a single factor does not account for all covariances among the items, it would be better to control for this effect at the research design stage. For example, future research should collect the data from separate sources, by following Demerouti et al. (2011) suggestion to use otherrated measures to capture an individual's PsyCap such as asking partners, supervisors and other acquaintances to rate his/her psychological capital.

Additionally, data should be collected at different point in time, in order to allow verification of the predictive validity and test-retest reliability of the instrument, particularly in relations to similar, albeit trait-like constructs, such as locus of control, in order to allow for investigation of the proposed state-like nature of PsyCap. Future research aimed at further establishing the psychometric properties of CPC-12, should particularly focus on test-retest reliability and withinsubject variability implementing true longitudinal designs (Dawkins et al., 2013; Nunnally, 1978).

Another potential limitation of our research is the use of convenience samples, which restrict the generalizability of the results.

Moreover, an important limitation was the size of the groups when testing measurement equivalence across gender. Previous research has showed that the number of participants can affect the power of the tests for measurement invariance (Putnick \& Bornstein, 2016; Reise et al., 1993), by lowering the test's sensitivity for sample sizes of 100 (Meade, 2015). Therefore, it is important for future research to involve larger samples in order to obtain more accurate estimates.

Finally, further studies involving other countries are needed to verify whether the same factor solution, with four dimensions loading to the higher-order PsyCap, is found to best fit the data.

Despite these limitations, however, the results lead to important suggestions for future research and interventions; the present findings show CPC-12 to display an excellent fit plus good discriminant, convergent, criterion and construct validities, as well as good reliability. The high correlations of the measure with problem-solving self-efficacy and proactive personality support the compound scale to become a focus of research in positive psychology and to be used within intervention programmes aimed at developing psychological capital at schools, universities and any other sector where the individual's well-being is concerned (i.e., in career coaching and counselling). Additionally, and with specific reference to the context of Human Resource Management, psychological capital has been shown to impact some important outcomes in work settings, by appearing to provide individuals with "the mental hardiness to effectively cope with job-related demands" (Baron et al., 2016, p. 747). This means that this second-order variable can represent an effective buffer against high level of stress (Baron et al., 2016) by involving self-cognitions of being able to cope with the job demands (i.e., self-efficacy), the belief in positive outcomes (i.e., optimism), the ability to imagine alternative pathways to overcome challenges (i.e., hope) and the capacity to react to those challenges and setbacks (i.e., resilience). Hence, CPC12 can and should be used also to assess psychological capital as a protective factor against work-related stressors and their related consequences (i.e., burnout).

International research has demonstrated that PsyCap can enhance several desirable outcomes and connects to a wide variety of other positive psychological constructs. High correlations with well-being, life satisfaction and academic results make a case for non-domain specific measures of PsyCap to become a focus of prospective research in positive psychology (Seligman \& Csikszentmihalyi, 2000). 


\section{References}

Alarcon, G., Eschleman, K. \& Bowling, N. (2009). Relationships between personality variables and burnout: A meta-analysis. Work \& Stress, 23(3), 244-263

Alessandri, G., Borgogni, L., Consiglio, C. \& Mitidieri, G. (2015). Psychometric properties of the Italian version of the Psychological Capital Questionnaire. International Journal of Selection and Assessment, 23 (2), 149159. https://doi.org//: 10.1111/ijsa.12103.

Alessandri, G., Consiglio, C., Luthans, F. \& Borgogni, L. (2018). Testing a dynamic model of the impact of psychological capital on work engagement and job performance. Career Development International, 23(1), 33-47.

Arbuckle, J. L. (2012). IBM® SPSS® Amos ${ }^{\mathrm{TM}} 21$ : Users Guide. IBM, USA.

Aspinwall, L. G. (2005). The psychology of future-oriented thinking: From achievement to proactive coping, adaptation, and aging. Motivation and Emotion, 29, 203-235.

Avey, J. B., Reichard, R. S., Luthans, F., \& Mhatre, K. H. (2011). Metaanalysis of the impact of positive psychological capital on employee attitudes, behaviors, and performance. Human Resource Development Quarterly, 22, 127-152. https://doi.org//10.1002/hrdq.20070.

Avey, J. B., Richmond, F. L., \& Nixon, D. R. (2012). Leader positivity and follower creativity: An experimental analysis. Journal of Creative Behavior, 46, 99-118.

Bagozzi, R. (1994). Advanced topics in structural equation models. In Bagozzi R. (Ed.), Advanced methods of marketing research, 1-51. Cambridge: Blackwell Publishers.

Bandura, A. (1997). Self-efficacy: The exercise of control. New York, NY: Freeman.

Bandura, A. (2012). On the functional properties of perceived self-efficacy revisited. Journal of Management, 38, 9-44. https://doi.org/10.1177/0149206311410606.

Baron, R., Franklin, R., \& Hmieleski, K. (2016). Why Entrepreneurs Often Experience Low, Not High, Levels of Stress: The Joint Effects of Selection and Psychological Capital. Journal of Management, 42(3), 742-768. https://doi.org/10.1177/0149206313495411.

Beaton, D. E., Bombardier, C., Guillemin, F., \& Ferraz, M. B. (2000). Guidelines for the process of cross-cultural adaptation of self-report measures. Spine, 25(24), 3186-3191. http://dx.doi.org/10.1097/00007632-200012150-00014.

Brandtstädter J., \& Wentura D. (1994). Veränderungen der Zeit-und Zukunftsperspektive im Übergang zum höheren Erwachsenenalter: entwicklungspsychologische und differentielle Aspekte. Z Entwickl und Padagogis, 26, 2-21.

Byrne, B. M. (2008). Testing for multigroup equivalence of a measuring instrument: a walk through the process. Psicothema, 20, 872-882.

Byrne, B. M., Shavelson, R. J., \& Muthén, B. (1989). Testing for the equivalence of factor covariance and mean structures: The issue of partial measurement invariance. Psychological Bulletin, 105, 456-466.

Campbell, H. L., Barry, C. L., Joe, J. N., \& Finney, S. J., (2008). Configural, metric, and scalar invariance of the modified achievement goal questionnaire. Educational and Psychological Measurement 68, 988-1007.

Caprara, G.V., Vecchione, M., Alessandri, G., Gerbino, M. and Barbaranelli, C. (2011), The contribution of personality traits and self-efficacy beliefs to academic achievement: A longitudinal study. British Journal of Educational Psychology 81, 78-96

Chang, E. C., Chang, O. D., Martos, T., Sallay, V., Zettler, I., Steca, P., D’Addario, M., Boniwell, I., Pop, A., Tarragona, M., Slemp, G. R., Shin, J., de la Fuente, A. \& Cardeñoso, O. (2019). The positive role of hope on the relationship between loneliness and unhappy conditions in Hungarian young adults: How pathways thinking matters! The Journal of Positive Psychology, 14(6), 724-733

Cheavens, J. S., Heiy, J. E., Feldman, D. B., Benitez C. \& Rand, K. L. (2019). Hope, goals, and pathways: Further validating the hope scale with observer ratings, The Journal of Positive Psychology, 149(4), 452-462.

Chen, G., Gully, S. M., \& Eden, D. (2001). Validation of a new general selfefficacy scale. Organizational Research Methods, 4, 62-83.

Cheung, G. W. (2008). Testing equivalence in the structure, means, and variances of higher order constructs with structural equation modelling. Organizational Research Methods, 11, 593 - 613.
Cheung, G. W., \& Rensvold, R. B. (2002). Evaluating goodness-of-fit indexes for testing measurement invariance. Structural Equation Modelling, 9, 233-255.

Costantini, A., De Paola, F., Ceschi, A., Sartori, R., Meneghini, A. M. \& Di Fabio, A. (2017). Work Engagement and Psychological Capital in the Italian Public Administration: A New Resource-based Intervention Programme. SA Journal of Industrial Psychology 43.1, E1-E11.

Coutu, D. (2002). How Resilience Works. Harvard Business Review 80(5), 46 55.

Craparo, G., Magnano, P., Paolillo, A., \& Costantino, V. (2018). The Subjective Risk Intelligence Scale. The Development of a New Scale to Measure a New Construct. Current Psychology, 37, 966-981.

Culbertson, S. S., Fullagar, C. J., \& Mills, M. J. (2010). Feeling Good and Doing Great: The Relationship Between Psychological Capital and Well-Being. Journal of Occupational Health Psychology, 15(4), 421-433.

Cunningham C.J., De La Rosa, G. M. (2008). The interactive effects of proactive personality and work-family interference on well-being. Journal of Occupational Health Psychology, 13(3): 271-282.

Datu, J. A. D., King, R. B. \& Valdez, J. P. M. (2018) Psychological capital bolsters motivation, engagement, and achievement: Cross-sectional and longitudinal studies. The Journal of Positive Psychology, 13(3), 260-270.

Dawkins, S., Martin, A., Scott, J., \& Sanderson, K. (2013). Building on the positives: A psychometric review and critical analysis of the construct of Psychological Capital. Journal of Occupational and Organizational Psychology, 86, 348-370. http://dx.doi.org/10.1111/joop.12007.

Demerouti, E., van Eeuwijk, E., Snelder, M., \& Wild, U. (2011). Assessing the effects of a "personal effectiveness" training on psychological capital, assertiveness and self-awareness using self-other agreement. Career Development International, 16, 60-81. http: //dx.doi.org// 10.1108/13620431111107810.

Dickinson-Delaporte, S. J., \& Holmes, M. D. (2011). Threat appeal communications: The interplay between health resistance and cognitive appraisal processes. Journal of Marketing

Communications, 17, 107-125.

Dollwet, M., \& Reichard, R. (2014). Assessing cross-cultural skills: validation of a new measure of cross-cultural psychological capital, The International Journal of Human Resource Management, 25:12, 1669-1696, http://dx.doi.org// 10.1080/09585192.2013.845239.

Eden, D. (1988). Pygmalion, goal setting, and expectancy: Compatible ways to raise productivity. Academy of Management Review, 13, 639-652.

Farrell, A. M. (2010). Insufficient discriminant validity: A comment on Bove, Pervan, Beatty and Shiu (2009). Journal of Business Research, 63, 324-327. http://dx.doi.org/10.1016/j.jbusres.2009.05.003.

Fornell, C., \& Larcker, D. F. (1981). Evaluating structural equation models with unobservable variables and measurement error. Journal of marketing Research, 18, 39-50. DOI: 10.2307/3151312.

Fraccaroli, F. (2019). Capitale psicologico, motivazione e academic self. Quale influenza su comportamenti, atteggiamenti e prestazione degli studenti. In: Castelli, L., Marcionetti, J., Plata A. \& Ambrosetti, A. ed. 2nd International Conference on Well-being in Education Systems, 12-14 November 2019, Locarno. [Online]. Hogrefe, pp. 5-8. [Accessed 23 April 2020]. Available from: http://www2.supsi.ch/cms/wellbeing/wp-

con-

tent/uploads/sites/28/2019/11/2ndEdition_BookOfAbstract.pdf\#pa ge $=18$.

Fredrickson, B. L. (2001). The role of positive emotions in positive psychology: The broaden-and-build theory of positive emotions. American Psychologist, 56, 218-226. http://dx.doi.org/10.1037/0003066X.56.3.218

Geldenhuys, M., Laba, K., \& Venter, C.M. (2014). Meaningful work, work engagement and organisational commitment. SA Journal of Industrial Psychology/SA Tydskrif vir Bedryfsielkunde, 40(1), 1-10.

Glaesmer, H., Hoyer, J., Klotsche, J., \& Herzberg, P. Y. (2008). Die deutsche version des Life-Orientation-Tests (LOTR) zum dispositionellen Optimismus und Pessimismus. Zeitschrift für Gesundheitswissenschaften, 16, 26-31. http://dx.doi.org/10.1026/0943-8149.16.1.26. 
Görgens-Ekermans, G., \& Steyn, R. (2016). Optimism, self-efficacy and meaningfulness: A structural model of subjective well-being at work. Management Dynamics: Journal of the Southern African Institute for Management Scientists, 25(4), 34-51.

Grether, T., Sowislo, J. F. \& Wiese, B. S. (2018). Top-down or Bottom-up? Prospective Relations between General and Domain-specific Selfefficacy Beliefs during a Work-family Transition. Personality and Individual Differences, 121: 131-39.

Hackman, R. (2009). "The perils of positivity." Journal of Organizational Behavior, 30, 309-319. https://doi.org/10.1002/job.587

Hair, J. F., Black, W. Babin, B. J., Anderson, R. E., \& Tatham, R. L. (2006). Multivariate data analysis (6th ed.). Upper Saddle River, NJ: Pearson Prentice Hall.

Harms, P., Vanhove, A., \& Luthans, F. (2017). Positive Projections and Health: An Initial Validation of the Implicit Psychological Capital Health Measure. Applied Psychology, 66(1), 78-102. doi: 10.1111 /apps.12077.

Hirschi, A. (2014). Hope as a resource for self-directed career management: Investigating mediating effects on proactive career behaviors and life and job satisfaction. Journal of Happiness Studies, 15, 1495-1512.

Hirschi, A., Abessolo, M., \& Froidevaux, A. (2015). Hope as a resource for career exploration: Examining incremental and cross-lagged effects. Journal of Vocational Behavior, 86, 38-47.

Hobfoll, S. E. (1989). Conservation of resources: A new attempt at conceptualizing stress. American Psychologist, 44, 513-524.

Hobfoll, S. E. (1998). Stress, culture, and community: The psychology and philosophy of stress. New York, NY: Plenum.

Huang, L. \& Luthans, F. (2015), Toward Better Understanding of the Learning Goal Orientation-Creativity Relationship: The Role of Positive Psychological Capital. Applied Psychology, 64, 444-472.

Hyo, S. J. \& Yoon, H. H. (2015). The impact of employees' positive psychological capital on job satisfaction and organizational citizenship behaviors in the hotel. International Journal of Contemporary Hospitality Management, 27(6), 1135-1156.

In, H. (2016). Acculturation and hope as predictors of career decision selfefficacy among korean international undergraduate students. Journal of Career Development, 43(6), 526-540.

Ironson, G., Balbin, E., Stuetzle, R., Fletcher, M., O'Cleirigh, A., Laurenceau, C., Schneiderman, J. \& Solomon, P. (2005). Dispositional Optimism and the Mechanisms by Which It Predicts Slower Disease Progression in HIV: Proactive Behavior, Avoidant Coping, and Depression. International Journal of Behavioral Medicine, 12(2), 86-97.

Jerusalem, M., Schwarzer, R. (1999). Allgemeine Selbstwirksamkeit. In: Schwarzer, R., Jerusalem, M., (Ed.), Skalen zur Erfassung von Lehrer-und Schülermerkmalen (p. 13-14). Berlin: Freie Universität Berlin.

Jiang, J. Y., Tsui, A. S., \& Li, J. (2015). Servant leadership, changes in personal values, and job meaningfulness. Academy of Management Best Papers Proceedings, $1 .$.

Leppert, K., Koch, B., Brähler, E., \& Strauß, B. (2008). Die Resilienzskala (RS)-Überprüfung der Langform RS-25 und einer Kurzform RS-13. Klinische Diagnostik. und Evaluation, 1, 226-243.

Li, M.-h., Eschenauer, R. \& Yang, Y. (2013), Influence of Efficacy and Resilience on Problem Solving in the United States, Taiwan, and China. Journal of Multicultural Counseling and Development, 41, 144-157.

Li, M.-h., Eschenauer, R. \& Persaud, V. (2018), Between Avoidance and Problem Solving: Resilience, Self-Efficacy, and Social Support Seeking. Journal of Counseling \& Development, 96, 132-143.

Little, L., Gooty, J., \& Nelson, D. (2007). Positive psychological capital: Has positivity clouded measurement rigour? In D. L. Nelson \& C. L. Cooper (Eds.), Positive organizational behavior: Accentuating the positives at work (pp. 191-209). London, UK: Sage. http://dx.doi.org/10.4135/9781446212752.n14.

Lorenz, T., Beer, C., Pütz, J., \& Heinitz, K. (2016). Measuring Psychological Capital: Construction and Validation of the Compound PsyCap Scale (CPC-12). PLOS ONE, 11(4): e0152892. doi:10.1371/journal. pone. 0152892 .

Luthans, B. C., Luthans, K. W., \& Jensen, S. M. (2012). The Impact of Business School Students' Psychological Capital on Academic Performance. Journal of Education for Business, 87(5), 253-259.
Luthans, F. (2002). Positive organizational behavior: Developing and managing psychological strengths. Academy of Management Executive, 16, 5772

Luthans, F., \& Youssef, C. M. (2004). Human, social, and now positive psychological capital management. Organizational Dynamics, 33, 143-160.

Luthans, F., Avey, J. B., Avolio, B., \& Peterson, S. (2010). The development and resulting performance impact of positive psychological capital. Human Resource Development Quarterly, 270, 41-67.

Luthans, F., Avolio, B. J., Avey, J. B., \& Norman, S. M. (2007). Positive psychological capital: Measurement and relationship with performance and satisfaction. Personnel Psychology, 60, 541-572.

Luthans, F., Avolio, B.J., Walumbwa, F.O. \& Li, W. (2005). The psychological capital of Chinese workers: exploring the relationship with performance. Management and Organization Review 1(2), 249-271

Luthans, F., Norman, S. M., Avolio, B. J., \& Avey, J. B. (2008). The mediating role of psychological capital in the supportive organizational climate-employee performance relationship. Journal of Organizational Behav ior, 29, 219-238.

Luthans, F., Vogelgesang, G. R., \& Lester, P. B. (2006). Developing the psychological capital of resiliency. Human Resource Development Review, 5, 25-

Luthans, F., Youssef, C. M., \& Avolio, B. J. (2007). Psychological capital. New York: Oxford University Press.

Macdonald, S. \& MacIntyre, P. D. (1997). The generic job satisfaction scale: Scale development and its correlates. Employee Assistance Quarterly, 13(2), $1-16$

Magnano, P., Paolillo, A., \& Giacominelli, B. (2015). Dispositional Optimism as a Correlate of Decision-Making Styles in Adolescence. $S A G E$ Open 5(2), 1-12.

Magnano, P., Craparo G. \& Paolillo, A. (2016). Resilience and Emotional Intelligence: Which Role in Achievement Motivation. International Jour nal of Psychological Research 9(1): 9-20.

Masten, A. S., \& Reed, M. G. J. (2002). Resilience in development. In C. R. Snyder, \& S. Lopez (Eds.), Handbook of positive psychology (pp. 74-88). Oxford, UK: OUP

Meade, A. W. (2005, April). Sample Size and Tests of Measurement Invariance. Paper presented at the 20th Annual Conference of the Society for Industrial and Organizational Psychology, Los Angeles, CA.

Meade, A. W., Johnson, E. C., \& Braddy, P. W. (2008). Power and sensitivity of alternative fit indices in tests of measurement invariance. Journal of Applied Psychology, 93(3), 568-592.

Newman, A., Ucbasaran, D., Zhu, F., \& Hirst, G. (2014). Psychological capital: A review and synthesis. Journal of Organizational Behaviour, 35, 120138. https://doi.org/10.1002/job.1916.

Nunnally, J. C. (1978). Psychometric theory (2nd ed.). New York: McGraw-Hill.

Olivier, A.L., \& Rothmann, S. (2007). Antecedents of work engagement in a multinational oil company. South African Journal of Industrial Psychology, 33(3), 49-56.

Parker, S. (1998). Enhancing role-breadth self-efficacy: The roles of job enrichment and other organizational interventions. Journal of Applied Psychology, 83, 835-852.

Peterson, S. J., Luthans, F., Avolio, B. J., Walumbwa, F. O., \& Zhang, Z. (2011). Psychological capital and employee performance: A laten growth modelling approach. Personnel Psychology, 64, 427-450. https://doi.org/10.1111/j.1744-6570.2011.01215.x.

Pisanu, F., \& Fraccaroli, F. (2019). Caratteristiche psicosociali apprendimento degli studenti. Evidenze empiriche e riflessioni. In D. Checchi \& G. Chiosso (Ed.), È possibile una scuola diversa? Una ricerca sperimentale per migliorare la qualità scolastica (pp. 195-226). Bologna, Italy: Il Mulino.

Platania S., Gruttadauria, S., Citelli, G., Giambrone L. \& Di Nuovo, S (2017). Associations of Thalassemia Major and satisfaction with quality of life: The mediating effect of social support, Health Psychology Open, July-December 2017: 1-9. DOI: 10.1177/2055102917742054.

Platania S., Castellano S., Petralia M.C., Santisi G. (2019). The mediating effect of the impact of quality of life on the relationship between job satisfaction and perceived stress of professional caregivers, Psicologia della salute, 1, 64-83. 10.3280/PDS2019-001004. 
Putnick, D. L., \& Bornstein, M. H. (2016). Measurement Invariance Conventions and Reporting: The State of the Art and Future Directions for Psychological Research. Developmental Review, 41, 71-90.

Raykov, T. (1998). Coefficient alpha and composite reliability with interrelated nonhomogeneous items. Applied Psychological Measurement, 22, 375385.

Rego, A., Sousa, F., Marques, C., \& Cunha, M. P. (2012). Authentic leadership promoting employees' psychological capital and creativity. Journal of Business Research, 65, 429-437.

Reise, S. P., Widaman, K. F., \& Pugh, R. H. (1993). Confirmatory factor analysis and item response theory: Two approaches for exploring measurement invariance. Psychological Bulletin, 114, 552-566.

Santilli, S., Marcionetti, J., Rochat, S., Rossier, J., \& Nota, L. (2017). Career Adaptability, Hope, Optimism, and Life Satisfaction in Italian and Swiss Adolescents. Journal of Career Development, 44(1), 62-76.

Scheier, M. F., \& Carver, C. S. (1985). Optimism, coping, and health: Assessment and implications of generalized outcome expectancies. Health Psychology, 4, 219-247.

Scheier, M. F., Carver, C. S., \& Bridges, M. W. (2001). Optimism, pessimism, and psychological well-being. In E. C. Chang (Ed.), Optimism \& pessimism: Implications for theory, research, and practice (pp. 198-216). Washington DC: APA.

Schwarzer, R., \& Schmitz, G.S. (1999). Kollektive Selbstwirksamkeitserwartung von Lehrern. Eine Längsschnittstudie in zehn Bundesländern. In: Zeitschrift für Sozialpsychologie 30, S. 262274.

Schure, M.B., Odden, M., Goins, R.T. (2013). The association of resilience with mental and physical health among older American Indians: the Native Elder Care Study. American Indian and Alaska Native Mental Health Research, 20, 27-41.

Schyns, B., \& Von Collani, G. (2002). A new occupational self-efficacy scale and its relation to personality constructs and organizational variables. European Journal of Work and Organizational Psychology, 11(2), 219-241.

Seibert, S. E., Crant, J. M., \& Kraimer, M. L. (1999). Proactive personality and career success. Journal of Applied Psychology, 84, 416-427.

Seligman, M.E., \& Csikszentmihalyi, M. (2000). Positive psychology: An introduction. The American Psychologist, 55(1), 5-14. PMID: 11392865.

Seligman, M. E. P. (1998). Learned optimism. New York, NY: Pocket Books.

Shelton, S. H. (1990). Developing the construct of general self-efficacy. Psychological Reports, 66, 987-994.
Sherer, M., Maddux, J. E., Mercadante, B., Prentice-Dunn, S., Jacobs, B., \& Rogers, R. W. (1982). The self-efficacy scale: Construction and validation. Psychological Reports, 51, 663-671.

Snyder, C. R. (2002). Hope theory: Rainbows in the mind. Psychological Inquiry, 13, 249-275.

Snyder, C. R., Sympson, S. C., Michael, S. T, \& Cheavens, J. (2001). Optimism and hope constructs: Variants on a positive expectancy theme. In E. C. Chang (Ed.), Optimism and pessimism: Implications for theory, research, and practice (pp. 101-125). Washington, DC: American Psychological Association.

Snyder, C. R., Sympson, S., Ybasco, F., Borders, T., Babyak, M., \& Higgins, R. (1996). Development and validation of the state hope scale. Journal of Personality and Social Psychology, 70, 321-335.

Spreitzer, G. (1995). Psychological empowerment in the workplace: Dimensions, measurement and validation. Academy of Management Journal, 38(5), 1442-1465. http://dx.doi.org/10.2307/256865

Stajkovic, A. D., \& Luthans, F. (1998). Self-efficacy and work-related performance: A meta-analysis. Psychological Bulletin, 124, 240-261.

Sweetman, D., Luthans, F., Avey, J. B., \& Luthans, B. C. (2011). Relationship between positive psychological capital and creative performance. Canadian Journal of Administrative Sciences, 28, 4-13.

Tabachnick, B.G. \& Fidell, L.S. (2007). Using Multivariate Statistics (5th edn). Boston, MA: Allyn \& Bacon.

Trifiletti, E., Capozza, D., Pasin, A., \& Falvo, R. (2009). A validation of the proactive personality scale. Testing, Psychometrics, Methodology in Applied Psychology, 16, 77-93. ISSN: 1972-6325.

Tugade, M. M., \& Fredrickson, B. L. (2004). Resilient individuals use positive emotions to bounce back from negative emotional experiences. Journal of Personality and Social Psychology, 86, 320-333.

Vandenberg, R. J., \& Lance, C. E. (2000). A review and synthesis of the measurement invariance literature: Suggestions, practices, and recommendations for organizational research. Organizational Research Methods 3, $4-69$.

Van De Schoot, R., Lugtig, P. \& Hox, J. (2012) A checklist for testing measurement invariance. European Journal of Developmental Psychology, 9, 486-492.

Wagnild, G. M., \& Young, H. M. (1993). Development and psychometric evaluation of the resiliency scale. Journal of Nursing Management, 1(2), 165-178. 